\title{
Multi-scale auroral observations in Apatity: winter 2010-2011
}

\author{
B. V. Kozelov, S. V. Pilgaev, L. P. Borovkov, and V. E. Yurov \\ Polar Geophysical Institute, Apatity, Murmansk region, 184209, Russia \\ Correspondence to: B. V. Kozelov (boris.kozelov@gmail.com)
}

Received: 22 November 2011 - Published in Geosci. Instrum. Method. Data Syst. Discuss.: 9 December 2011

Revised: 20 February 2012 - Accepted: 1 March 2012 - Published: 6 March 2012

\begin{abstract}
Routine observations of the aurora are conducted in Apatity by a set of five cameras: (i) all-sky TV camera Watec WAT-902K (1/2"CCD) with Fujinon lens YV2.2 × 1.4ASA2; (ii) two monochromatic cameras Guppy F-044B NIR $\left(1 / 2^{\prime \prime} \mathrm{CCD}\right)$ with Fujinon HF25HA-1B (1:1.4/25 mm) lens for $18^{\circ}$ field of view and glass filter $558 \mathrm{~nm}$; (iii) two color cameras Guppy F-044C NIR (1/2"CCD) with Fujinon DF6HA$1 \mathrm{~B}(1: 1.2 / 6 \mathrm{~mm})$ lens for $67^{\circ}$ field of view. The observational complex is aimed at investigating spatial structure of the aurora, its scaling properties, and vertical distribution in the rayed forms. The cameras were installed on the main building of the Apatity division of the Polar Geophysical Institute and at the Apatity stratospheric range. The distance between these sites is nearly $4 \mathrm{~km}$, so the identical monochromatic cameras can be used as a stereoscopic system. All cameras are accessible and operated remotely via Internet. For 2010-2011 winter season the equipment was upgraded by special blocks of GPS-time triggering, temperature control and motorized pan-tilt rotation mounts. This paper presents the equipment, samples of observed events and the web-site with access to available data previews.
\end{abstract}

\section{Introduction}

Aurora is one of the most spectacular events in Nature. While the main physical processes leading to auroral luminosity are known, there is no unique theory to explain the whole variety of auroral structures. Moreover, there is no common view on such important for plasma physics auroral characteristic as minimal (or typical) width of auroral arcs and filaments (Maggs and Davis, 1968; Borovsky et al., 1991; Partamies et al., 2010; Sandahl et al., 2008). Many authors pointed out that the results strongly depend on instrumentation details: the field of view and sensitivity of auroral camera, filters, distortions, etc. (Knudsen et al., 2001; Dahlgren et al., 2008).
In the last decade, new ideas of turbulence and selforganized criticality originally developed for description of plasma complexity were applied to explain auroral structures (Uritsky et al., 2002; Kozelov, 2003; Kozelov et al., 2004; Kozelov and Rypdal, 2007). In this approach statistical distributions are treated and scaling features described by the fractal geometry of Nature are explored (Mandelbrot, 1983). To derive them from observations, we need information on distribution of auroral luminosity in a wide range of spatial scales. The only way to obtain such information is simultaneous observations by cameras with different fields of view. Thus, in addition to traditional all-sky cameras, we need observations by cameras with narrow field of view directed to magnetic zenith where the smallest scales can be better resolved.

The aspect angle distortion (the perspective effect) is another problem which is met by investigators of the auroral structure. There are two ways to treat it into account: (i) to correct for this distortion in the statistical model of data analysis (see, e.g. Kozelov and Golovchanskaya, 2010), and (ii) to exclude it by tomography reconstruction (Gustavsson, 1998). In the latter case, simultaneous observations from spatially separated points are needed.

Pulsating aurora which is frequently observed in the morning side of the auroral oval and equatorward from bright auroral arcs is another point of investigation (Omholt, 1971; Brekke, 1972; Brown et al., 1976; Yamamoto, 1988; Tagirov et al., 1999; Sato et al., 2002; Jones et al., 2011). It is usually associated with regions of VLF wave interactions with energetic electrons. However additional experimental information on the temporal and spatial features of pulsating structures is needed to build a detailed theory of this phenomenon (Trakhtengerts et al., 2004; Kozelov and Vjalkova, 2005).

Here we present a low-cost observational system which meets the major requirements mentioned above. The complex was started in 2008 from one digital camera shared by Torsten Aslaksen (University of Troms $\varnothing$, Troms $\varnothing$, Norway) 


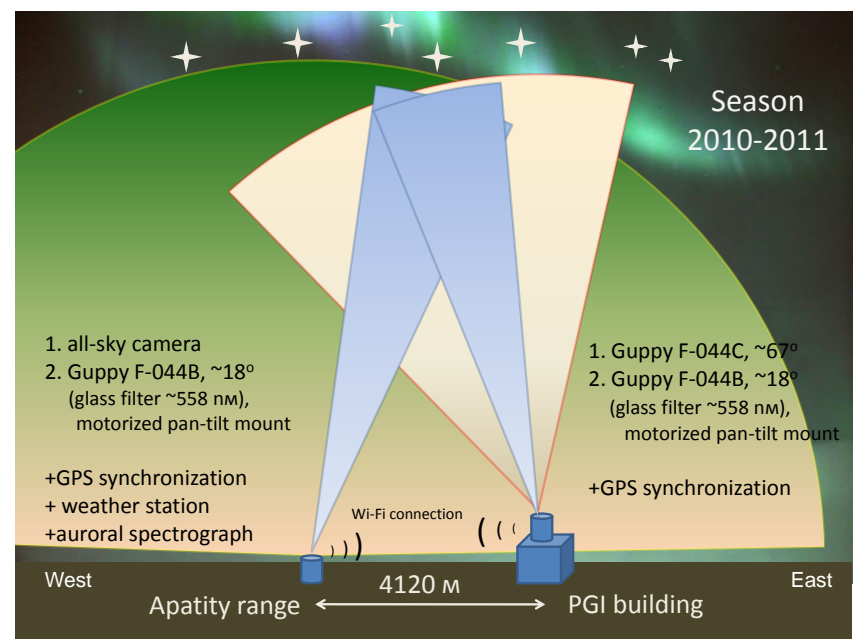

Fig. 1. Location of the cameras during 2010-2011 winter season.

for winter 2008-2009. After that season we recognized a possibility of auroral observations by low-cost digital cameras and started building the complex. The report presents the equipment details actual for 2010-2011 winter season, observations, and web-interface to access to the data previews.

\section{Equipments}

A schema of the observational system is shown in Fig. 1. Four cameras were operated automatically during dark time, independently of weather conditions. The main characteristics of the cameras are summarized in Table 1. The cameras were installed on the main building of the Apatity division of the Polar Geophysical Institute (PGI) and at Apatity stratospheric range. More information on the cameras is available at vendor's web-sites http://www.alliedvisiontec.com and http://www.wateccameras.com. Here we only mention that the cameras contain the most sensitive non-intensified Sony CCD sensors of TV format.

Each camera is placed in an individual housing box with a heater located near the input glass window. Unfortunately, the AVT Guppy cameras have no internal temperature detectors at the CCD sensors; therefore we can control the temperature only by sensors which are put on the camera surface. Narrow field of view cameras were mounted on industrial pan-tilt motorized mounts to fit the direction of observation. All cameras were directed to a region near magnetic zenith. The distance between the points of observation is $4120 \mathrm{~m}$, so identical monochromatic cameras can be used as a stereoscopic system to resolve auroral structures at altitudes of 90 $300 \mathrm{~km}$.

The data storage from cameras \#1-4 was provided by Linux-based programs. All cameras, data storage computers, and motorized mounts are remotely accessible and operated through network connections.

A special module was developed for precise generation of all time pulses: for triggering image capture by the cameras, for time synchronization of data storage computers, and for operation by the pan-tilt motors. The module was also used to collect information from temperature sensors in the housing boxes. The module uses an industrial Lassen SK II GPS Module (see more details here: http://www.prin.ru/ equipment/gps_modules) completed by original microcontroller based on PIC-controller PIC18F452. The schema of the synchronization module is shown in Fig. 2. The modules were installed at both points of observations to avoid possible interruptions in the Wi-Fi connection. The estimated precision of time synchronization for simultaneous images is better than a few milliseconds, which is a good precision for auroral observations.

One more camera (\#5) was manually operated during good weather conditions. This camera was the same as number 4 in Table 1 but located at position $67^{\circ} 33^{\prime} \mathrm{N}, 33^{\circ} 25^{\prime} \mathrm{E}$ and usually directed to the North. The intervals of observations are available here: http://sites.google.com/site/ auroraobservations/.

\section{Observational data and examples of data analysis}

Real time images from the cameras were available on-line at web-sites http://aurora.pgia.ru/ and http://db.pgia.ru/cam/. Automatically generated web-archive for each camera contains monthly overviews, daily and hourly keograms, and individual images in JPG format with $10 \mathrm{~s}$ resolution. Original uncompressed frames with $1 \mathrm{~s}$ resolution are available by request. On-line journal of hardware modifications is accessible at web-site http://sites.google.com/site/ auroraobservations/. The same site contains keograms from North-directed color camera (\#5), where auroral activity was observed during nearly all nights under good weather conditions. Unfortunately, because of bad weather conditions and low solar activity during 2010-2011 winter season there were few days of aurora observations near zenith in Apatity. One of them was a day of magnetic storm on 4 February 2011. Figure 3 presents samples of auroral structures observed simultaneously by the camera set during this event (see also file AP_2011-02-04-18-16-30_1min.avi in the Supplement).

The auroral structure observed by camera \#4 can be used to examine scaling features of spatial distribution of auroral luminosity. A wavelet method, which was developed by Abry et al. (2000), was shown to have some principal advantages over traditional spectral approaches. This method was previously applied to auroral observations and discussed in details in Golovchanskaya et al. (2008); Kozelov and Golovchanskaya (2010). The method consists of discrete wavelet transform of the data over dyadic grid, computation 
Table 1. Characteristics of the auroral cameras.

\begin{tabular}{|c|c|c|c|c|c|c|c|}
\hline \# & Camera & Interface & Lens & $\begin{array}{c}\text { Field } \\
\text { of view }\end{array}$ & Position & $\begin{array}{c}\text { Data } \\
\text { resolution }\end{array}$ & $\begin{array}{l}\text { Operation } \\
\text { time }\end{array}$ \\
\hline 1 & $\begin{array}{l}\text { Watec } \\
\text { WAT- } \\
902 \mathrm{~K}\end{array}$ & $\begin{array}{l}\text { Analog } \\
\text { video with } \\
\text { frame } \\
\text { grabber }\end{array}$ & $\begin{array}{c}\text { Fujinon } \\
\text { YV2.2 } \times \\
1.4 \mathrm{~A}-\mathrm{SA} 2\end{array}$ & $180^{\circ}$ & $\begin{array}{l}67^{\circ} 34^{\prime} \mathrm{N} \\
33^{\circ} 18^{\prime} \mathrm{E}\end{array}$ & $\begin{array}{c}232 \times 232, \\
16 \text { bits, } 1 \mathrm{~s}, \\
24 \text { integrated } \\
\text { frames }\end{array}$ & $\begin{array}{l}28 \mathrm{Dec} \\
2010- \\
14 \mathrm{Apr} \\
2011\end{array}$ \\
\hline 2 & $\begin{array}{c}\text { AVT } \\
\text { Guppy } \\
\text { F-044B } \\
\text { NIR }\end{array}$ & $\begin{array}{l}\text { IEEE } \\
1394 \mathrm{a}\end{array}$ & $\begin{array}{l}\text { Fujinon } \\
\text { HF25HA-1B } \\
\text { glass filter } \\
\sim 558 \mathrm{~nm}\end{array}$ & $\begin{array}{c}15^{\circ} \times 10^{\circ} \\
18^{\circ} \text { diagonal }\end{array}$ & $\begin{array}{l}67^{\circ} 34^{\prime} \mathrm{N} \\
33^{\circ} 18^{\prime} \mathrm{E}\end{array}$ & $\begin{array}{c}376 \times 288 \\
8 \text { bits, } 1 \mathrm{~s}\end{array}$ & $\begin{array}{c}28 \mathrm{Dec} \\
2010- \\
14 \mathrm{Apr} \\
2011\end{array}$ \\
\hline 3 & $\begin{array}{c}\text { AVT } \\
\text { Guppy } \\
\text { F-044B } \\
\text { NIR }\end{array}$ & $\begin{array}{l}\text { IEEE } \\
1394 \mathrm{a}\end{array}$ & $\begin{array}{l}\text { Fujinon } \\
\text { HF25HA-1B } \\
\text { glass filter } \\
\sim 558 \mathrm{~nm}\end{array}$ & $\begin{array}{c}15^{\circ} \times 10^{\circ} \\
18^{\circ} \text { diagonal }\end{array}$ & $\begin{array}{l}67^{\circ} 34^{\prime} \mathrm{N} \\
33^{\circ} 24^{\prime} \mathrm{E}\end{array}$ & $\begin{array}{c}376 \times 288 \\
8 \text { bits, } 1 \mathrm{~s}\end{array}$ & $\begin{array}{l}20 \text { Oct } \\
2010- \\
14 \mathrm{Apr} \\
2011\end{array}$ \\
\hline 4 & $\begin{array}{c}\text { AVT } \\
\text { Guppy } \\
\text { F-044C } \\
\text { NIR }\end{array}$ & $\begin{array}{l}\text { IEEE } \\
1394 \mathrm{a}\end{array}$ & $\begin{array}{c}\text { Fujinon } \\
\text { DF6HA-1B }\end{array}$ & $\begin{array}{c}56^{\circ} \times 44^{\circ} \\
67^{\circ} \text { diagonal }\end{array}$ & $\begin{array}{l}67^{\circ} 34^{\prime} \mathrm{N} \\
33^{\circ} 24^{\prime} \mathrm{E}\end{array}$ & $\begin{array}{c}376 \times 290 \\
4 \text { colors } \\
\text { CMY+G, } \\
8 \text { bits, } 1 \mathrm{~s}\end{array}$ & $\begin{array}{c}20 \text { Oct } \\
2010- \\
14 \mathrm{Apr} \\
2011\end{array}$ \\
\hline
\end{tabular}

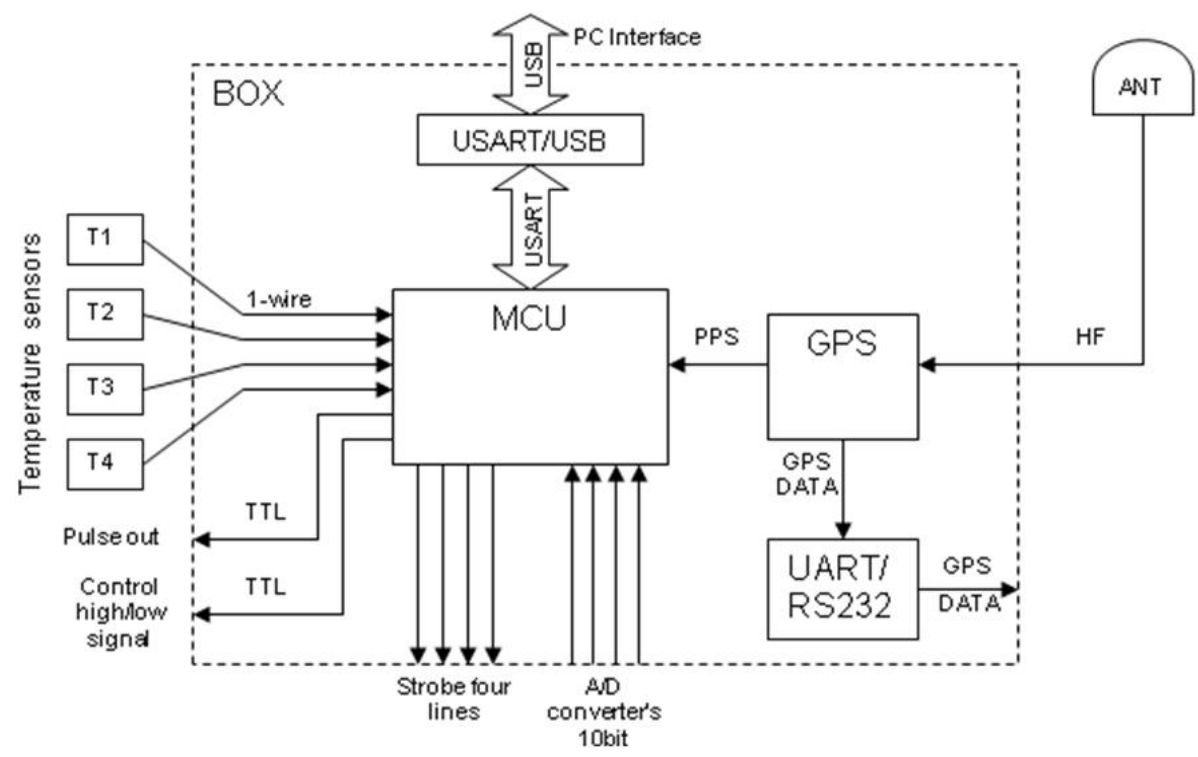

Fig. 2. Schema of synchronization module.

of the variance of the detail wavelet coefficients at each octave and estimation of the scaling index from the slope of the logarithmic plot of the dependence of the variance on octave. Unlike our previous studies, where isotropy of scaling features was assumed, here we present an example of similar analysis for anisotropic case. Figure 4 shows two images with different auroral structures observed on 4 February 2011. The overlapped polar plots present angular dependence of the scaling index. Here the index value is expressed by radial distance and the angle indicates the direction of a linear cross section of the image used for index calculation.
The dotted circles mark the extreme values of the scaling index. One can see that in the case of auroral arcs (Fig. 4a) the scaling index is strongly anisotropic and it reaches maximum $(\sim 2.8)$ in the direction normal to the arcs. For pulsating aurora (Fig. 4b), the scaling index is smaller $(<2.0)$ and the angular dependence is more isotropic. More extended analysis of scaling anisotropy will be published soon.

An example of observations of pulsating aurora with analysis of pulsating periods is shown in Fig. 5. The pulsating patches were observed for more than $2 \mathrm{~h}$ on 6 February 2011. Here we use an interval 01:00-02:00 UT, when 


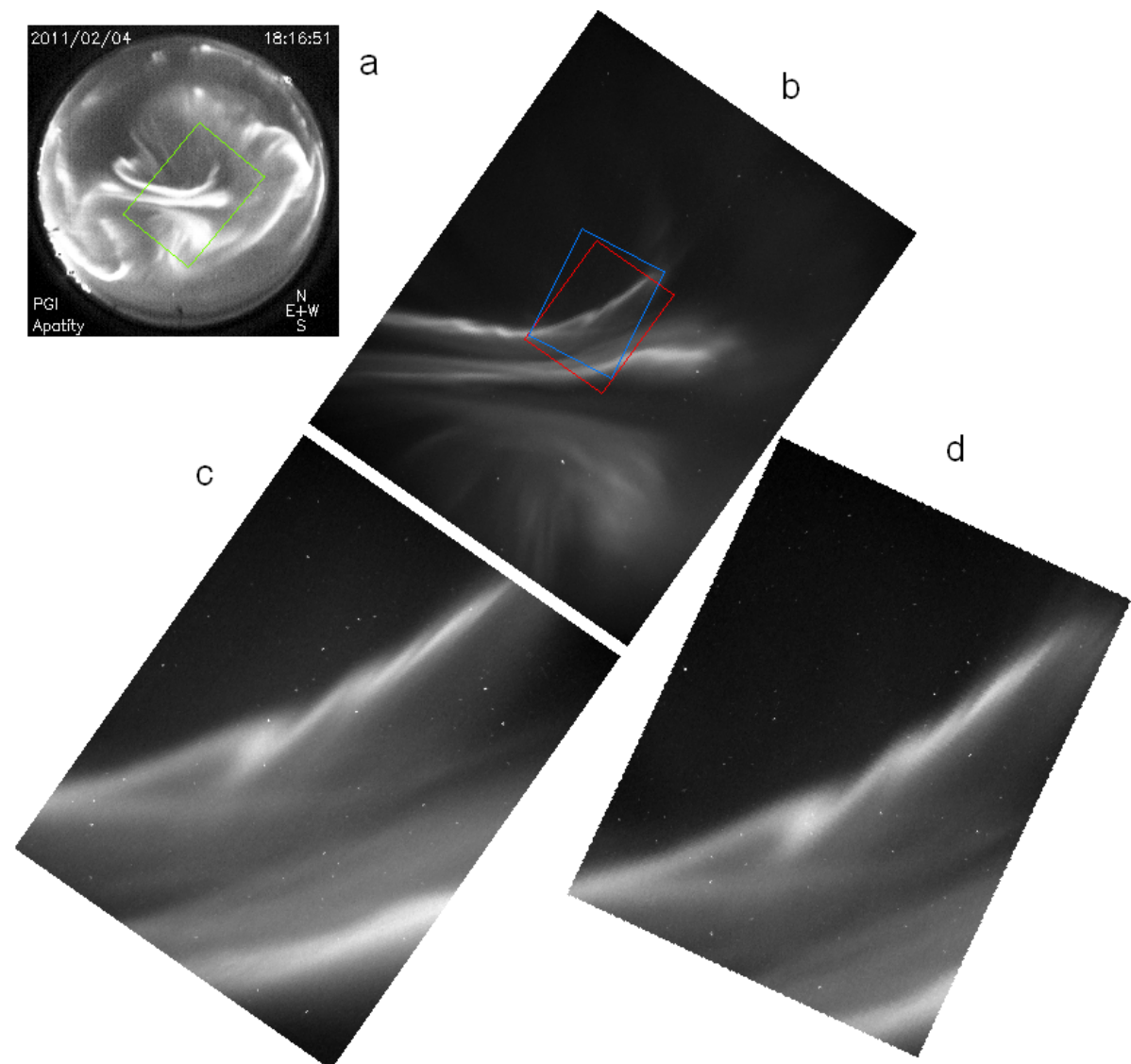

Fig. 3. Simultaneous observations by four auroral cameras listed in Table 1, 4 February, 18:16:51 UT: (a) - allsky camera (\#1), the green frame is the field of view $\left(67^{\circ}\right)$ of camera \#4; (b) - camera \#4 (green channel), the red and blue frames are the fields of view $\left(18^{\circ}\right)$ for cameras \#3 and \#2, correspondingly; (c) - camera \#3 (PGI building); (d) - camera \#2 (Apatity range).

\section{a}

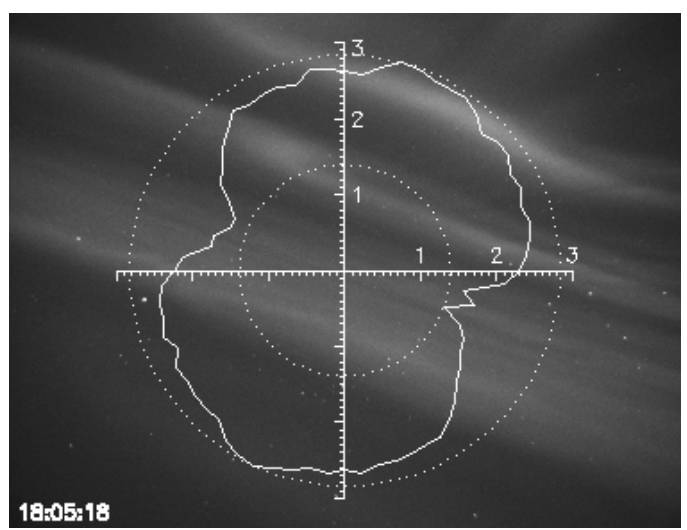

$b$

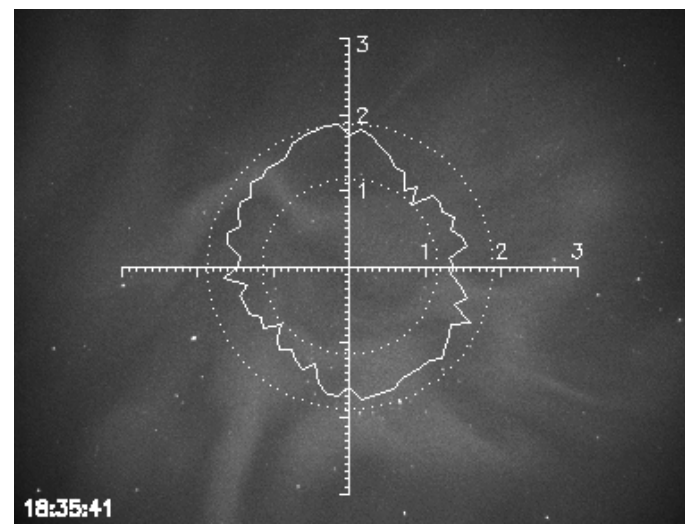

Fig. 4. Angular dependence of scaling index for spatial distribution of auroral luminosity registered by camera \#4 in green channel: (a) - system of auroral arcs, (b) - pulsating aurora.

patches occupied most part of the sky (see the image in Fig. 5a and file AP_2011-02-06-01-30_5min.avi in the Supplement). The central column of all-sky image corresponds to the North-South latitudinal cross section of the auroral region, and these columns for each image within $1-\mathrm{h}$ inter- val have been used to build a keogram. A short fragment of the keogram is shown in Fig. 5b. One can see pseudoperiodical pulsations distributed in the North-South direction. These periodicities in the range from 2 to $200 \mathrm{~s}$ were analyzed for each raw of the keogram. Figure 5c presents 


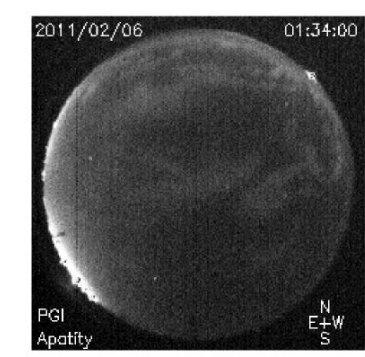

a
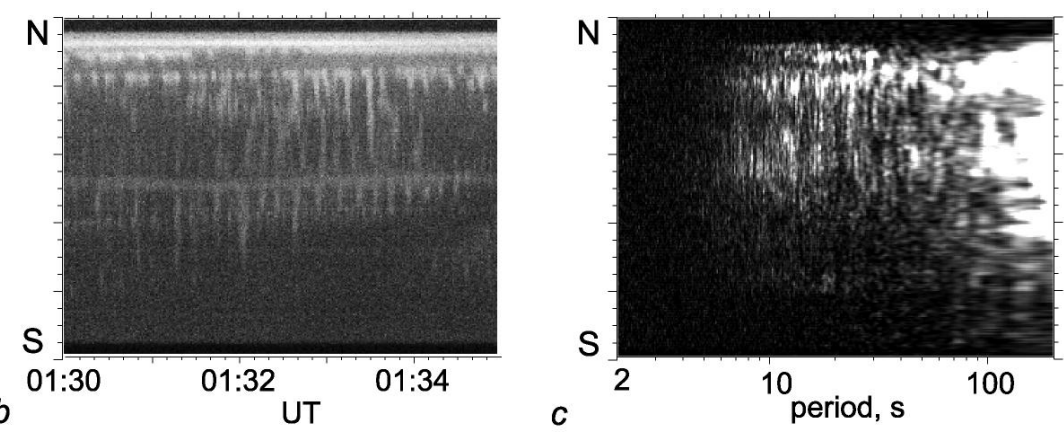

Fig. 5. Pulsating auroral patches registered by all-sky camera (\#1): (a) - example of image; (b) - fragment of keogram, 1-s resolution; (c) - periodogram calculated from keogram for interval 01:00-02:00 UT on 4 February 2011.

a resulted periodogram which characterizes spatial (in the North-South direction) distribution of auroral pulsations and its probable periods. Bright spots in the periodogram correspond to nearly periodical pulsations with a given period in a given position in the sky. One can see that, while the aurora is strongly variable on the timescales of minutes, there is appreciable pulsating activity on the scales from several seconds to tens of seconds. These features correspond well to previous observations (Brown et al., 1976; Yamamoto, 1988; Tagirov et al., 1999; Sato et al., 2002). The analysis will be continued for other events, and a detailed spatial structure of the patches will be extracted from data of other cameras.

A stereoscopic pair of cameras \#2 and \#3 enables altitude estimations. Stereoscopic or triangulation methods have been used to determine the altitude of auroras already in pioneering works of Störmer (Störmer, 1910, 1911). Later the stereo-imaging method was applied not only to measure the altitude of aurora (Stenbaek-Nielsen et al., 1978) but also to noctilucent clouds (Witt, 1962) and even to reconstruct a three-dimensional map of the $\mathrm{OH}$-layer centroid heights (Moreels et al., 2008). Through the last decades other method became more popular for studying aurora: more sophisticated tomography reconstruction, direct measurements by rockets and radars, theoretical estimation by transport model from measured parameters of precipitated flux of auroral particles. In our case the distance between observational points is relatively small, therefore we can use very simple mathematics for altitude estimates.

Here, we use simultaneous registration of bright satellite flash to demonstrate the altitude estimates. The motion of the satellite (possibly IRIDIUM 37) as a sequence of anaglyph stereo images is shown in a Supplement file AP_2011-0206-02-40-13_20s.avi. Due to the precise time synchronization of the cameras we can obtain visual parallax against the background of stars. The satellite is a very sharp object, so from stereo pairs of images the visual parallax is estimated as $7.5 \pm 0.5$ pixels, which corresponds to $\alpha=0.30^{\circ} \pm 0.02^{\circ}$ for angular resolution $\sim 0.04^{\circ}$ per pixel. Then the distance from observational point to the satellite is $d / \sin \alpha$, where $d=4.12 \mathrm{~km}$ is distance between observational points. Taking into account the elevation angle, $\psi$ (between the directions to the satellite and to the horizon), we deduce for the considered event:

$H=\frac{d \sin \psi}{\sin \alpha}=\frac{4.12 \sin 76^{\circ}}{\sin 0.30^{\circ}}=760 \pm 50 \mathrm{~km}$

This agrees quite well with typical altitudes of the IRIDIUM satellites. For auroral structures similar estimations give expected altitudes: $100-105 \mathrm{~km}$ for pulsing patches, 130 $140 \mathrm{~km}$ for quiet arcs, $150-200 \mathrm{~km}$ for rays. These are typical values known from the literature (Omholt, 1971; Brown et al., 1976). The estimations of aurora altitude by the camera system is possible if there is a structure with sharp luminosity gradient in the East-West direction. In such a case, the accuracy of the method is restricted by $1-2$ pixels discrepancy for visual parallax estimation, which for altitudes $100-120 \mathrm{~km}$ corresponds to $2-5 \mathrm{~km}$.

\section{Conclusions}

A new optical system for routine observations of auroral structures has been installed in Apatity, Murmansk region. The observation system provides information on auroral structures in three different fields of view: all-sky $\left(180^{\circ}\right), 67^{\circ}$ and $18^{\circ}$ (diagonal). Two spatially separated identical cameras gives us a possibility to use the images as a stereoscopic pair and extract information on the auroral structure in the plane perpendicular to the magnetic field lines.

The web-preview archive is accessible for event selection. Data analysis and observations will be continued next winter. The observational complex will be completed by an auroral spectrograph. The Apatity auroral spectrograph was described previously with an example of the combined protonelectron aurora event (Borovkov et al., 2005). The spectrograph will be upgraded for automatical operation with a system of auroral cameras described above. 
Supplementary material related to this article is available online at: http://www.geosci-instrum-method-data-syst.net/1/1/ 2012/gi-1-1-2012-supplement.zip.

Acknowledgements. This work was partly supported by the program "Plasma processes in the solar system" of Division of Physical Sciences of RAS and grant 11-02-00397 of Russian Foundation for Basic Researches.

Edited by: V. Korepanov

\section{References}

Abry, P., Flandrin, P., Taqqu, M. S., and Veitch, D.: Wavelets for the analysis, estimation and synthesis of scaling data, in: SelfSimilar Network Traffic and Performance Evaluation, edited by: Park, K. and Willinger, W., Wiley-Interscience, Hoboken, N. J., p. 39, 2000.

Brekke A.: Frequency of pulsating aurora and its relationship to other characteristic parameters, Planet. Space Sci., 20, 285-289, 1972.

Brown N., Davis T., Hallinan, T., and Stenbaek-Nielsen, H.: Altitude of pulsating aurora determined by a new instrumental technique, Geophys. Res. Lett., 3, 403-404, 1976.

Borovsky, J. E., Suszcynsky, D. M., Buchwald, M. I., and Dehavin, H. V.: Measuring the thickness of auroral curtains, Arctic, 44, 231-238, 1991.

Borovkov, L. P., Kozelov, B. V., Yevlashin, L. S., and Chernouss, S. A.: Variations of auroral hydrogen emission near substorm onset, Ann. Geophys., 23, 1623-1635, doi:10.5194/angeo-231623-2005, 2005.

Dahlgren, H., Ivchenko, N., Sullivan, J., Lanchester, B. S., Marklund, G., and Whiter, D.: Morphology and dynamics of aurora at fine scale: first results from the ASK instrument, Ann. Geophys., 26, 1041-1048, doi:10.5194/angeo-26-1041-2008, 2008.

Golovchanskaya, I. V., Kozelov, B. V., Sergienko, T. I., Brändström, U., Nilsson, H., and Sandahl, I.: Scaling behavior of auroral luminosity fluctuations observed by Auroral Large Imaging System (ALIS), J. Geophys. Res., 113, A10303, doi:10.1029/2008JA013217, 2008.

Gustavsson, B.: Tomographic inversion for ALIS noise and resolution, J. Geophys. Res., 103, 26621-26632, 1998.

Jones, S. L., Lessard, M. R., Rychert, K., Spanswick, E., and Donovan, E.: Large-scale aspects and temporal evolution of pulsating aurora, J. Geophys. Res., 116, A03214, doi:10.1029/2010JA015840, 2011.

Knudsen, D. J., Donovan, E. F., Cogger, L. L., Jackel, B., and Shaw, W. D.: Width and structure of mesoscale optical auroral arcs, Geophys. Res. Lett., 28, 705-708, 2001.

Kozelov, B. V.: Fractal approach to description of the auroral structure, Ann. Geophys., 21, 2011-2023, doi:10.5194/angeo21-2011-2003, 2003.

Kozelov, B. V. and Golovchanskaya, I. V.: Derivation of aurora scaling parameters from ground-based imaging observations: Numerical tests, J. Geophys. Res., 115, A02204, doi:10.1029/2009JA014484, 2010.
Kozelov, B. V. and Rypdal, K.: Spatial scaling of optical fluctuations during substorm-time aurora, Ann. Geophys., 25, 915-927, doi:10.5194/angeo-25-915-2007, 2007.

Kozelov, B. V. and Vjalkova, N. Y.: Search of temporal chaos in TV images of aurora, Int. J. Geomagn. Aeron., 5, GI3005, doi:10.1029/2005GI000102, 2005.

Kozelov, B. V., Uritsky, V. M., and Klimas, A. J.: Power law probability distributions of multiscale auroral dynamics from ground-based TV observations, Geophys. Res. Lett., 31, L20804, doi:10.1029/2004GL020962, 2004.

Maggs, J. E. and Davis, T. N.: Measurements of the thicknesses of auroral structures, Planet. Space Sci., 16, 205-209, 1968.

Mandelbrot, B. B.: The Fractal Geometry of Nature, New York, W. H. Freeman, 1983.

Moreels, G., Clairemidi, J., Faivre, M., Mougin-Sisini, D., Kouahla, M. N., Meriwether, J. W., Lehmacher, G. A., Vidal, E., and Veliz, O.: Stereoscopic imaging of the hydroxyl emissive layer at low latitudes, Planet. Space Sci., 56, 1467-1479, 2008.

Omholt, A.: The optical aurora, Springer-Verlag, 1971.

Partamies, N., Syrjäsuo, M., Donovan, E., Connors, M., Charrois, D., Knudsen, D., and Kryzanowsky, Z.: Observations of the auroral width spectrum at kilometre-scale size, Ann. Geophys., 28, 711-718, doi:10.5194/angeo-28-711-2010, 2010.

Sandahl, I., Sergienko, T., and Brandstrom, U.: Fine structure of optical aurora, J. Atmos. Sol.-Terr. Phy., 70, 2275-2292, 2008.

Sato, N., Wright, D., Ebihara, Y., Sato, M., Murata, Y., Doi, H., Saemundsson, T., Milan, S., Lester, M., and Carlson, C.: Direct comparison of pulsating aurora observed simultaneously by the FAST satellite and from the ground at Syowa, Geophys. Res. Lett., 29, 2041-2044, 2002.

Stenbaek-Nielsen, H. C., Hallinan, T. J., and Davis, T. N.: StereoTV Observations of Pulsating aurora, J. Geomag. Geoelectr., 30, 343-344, 1978.

Störmer, C.: Photographies des aurores boréales et nouvelle méthode pour mesurer leur altitude, Comptes Rendus de l'Académie des Sciences, 150, 1631-1634, 1910.

Störmer, C.: Résultats des mesures photogrammétriques de l'altitude de l'aurore boréale à Bosekop aux mois de frévrier et de mars 1910, Comptes Rendus de l'Académie des Sciences, 152, 1194-1196, 1911.

Tagirov, V. R., Ismagilov, V. S., Titova, E. E., Arinin, V. A., Perlikov, A. M., Manninen, J., Turunen, T., and Kaila, K.: Auroral pulsations and accompanying VLF emissions, Ann. Geophys., 17, 66-78, doi:10.1007/s00585-999-0066-9, 1999.

Trakhtengerts, V. Yu., Demekhov, A. G., Titova, E. E., Kozelov, B. V., Santolik, O., Gurnett, D., and Parrot, M.: Interpretation of Cluster data on chorus emissions using the backward wave oscillator model, Phys. Plasmas, 11, 1345-1351, 2004.

Uritsky, V. M., Klimas, A. J., Vassiliadis, D., Chua, D., and Parks, G.: Scale-free statistics of spatiotemporal auroral emissions as depicted by POLAR UVI images: Dynamic magnetosphere is an avalanching system, J. Geophys. Res., 107, 1426, doi:10.1029/2001JA000281, 2002.

Witt, G.: Height, structure and displacements of noctilucent clouds, Tellus, 14, 1-18, 1962.

Yamamoto, T.: On the temporal fluctuations of pulsating auroral luminosity, J. Geophys. Res., 93, 897-911, doi:10.1029/JA093iA02p00897, 1988. 